Article

\title{
Improving Seasonal Prediction of East Asian Summer Rainfall Using NESM3.0: Preliminary Results
}

\author{
Young-Min Yang ${ }^{1,2}\left(\mathbb{D}\right.$, Bin Wang ${ }^{1,2, *}$ and Juan $\mathrm{Li}^{1}{ }^{1}$ \\ 1 Key Laboratory of Meteorological Disaster of Ministry of Education and Earth System Modeling Center, \\ Nanjing University of Information Science and Technology, Nanjing 21044, China; \\ ymyang@hawaii.edu (Y.-M.Y.); juanl@hawaii.edu (J.L.) \\ 2 Department of Atmospheric Sciences and International Pacific Research Center, University of Hawaii, \\ Honolulu, HI 96822, USA \\ * Correspondence: wangbin@hawaii.edu
}

Received: 29 August 2018; Accepted: 5 December 2018; Published: 8 December 2018

\begin{abstract}
It has been an outstanding challenge for global climate models to simulate and predict East Asia summer monsoon (EASM) rainfall. This study evaluated the dynamical hindcast skills with the newly developed Nanjing University of Information Science and Technology Earth System Model version 3.0 (NESM3.0). To improve the poor prediction of an earlier version of NESM3.0, we modified convective parameterization schemes to suppress excessive deep convection and enhance insufficient shallow and stratiform clouds. The new version of NESM3.0 with modified parameterizations (MOD hereafter) yields improved rainfall prediction in the northern and southern China but not over the Yangtze River Valley. The improved prediction is primarily attributed to the improvements in the predicted climatological summer mean rainfall and circulations, Nino 3.4 SST anomaly, and the rainfall anomalies associated with the development and decay of El Nino events. However, the MOD still has biases in the predicted leading mode of interannual variability of precipitation. The leading mode captures the dry (wet) anomalies over the South China Sea (northern East Asia) but misplaces precipitation anomalies over the Yangtze River Valley. The model can capture the interannual variation of the circulation indices very well. The results here suggest that, over East Asia land regions, the skillful rainfall prediction relies on not only model's capability in predicting better summer mean and ENSO teleconnection with EASM, but also accurate prediction of the leading modes of interannual variability.
\end{abstract}

Keywords: East Asian summer monsoon; seasonal prediction; dynamic prediction; summer rainfall prediction; NESM3.0; ENSO teleconnection

\section{Introduction}

Seasonal prediction of the land monsoon precipitation has been an outstanding challenge since 1886 when Indian monsoon rainfall prediction started. Over the East Asia (EA) and western North Pacific region, the atmospheric general circulation models have notorious problems in simulation of the climatological monsoon trough and subtropical high as well as the subtropical frontal rain belt [1]. A particular challenge is that the vigorous monsoon-ocean interaction must be considered in the dynamic simulation and prediction of monsoon precipitation [2,3].

Seasonal predictions using coupled climate models have been progressively improved by continuous efforts to improve initializations, model physical parameterizations and horizontal and vertical resolutions [4,5]. Previous studies have shown considerable skills for prediction of East Asia summer monsoon (EASM) index. However, prediction of summer precipitation using coupled climate models remains at a very low-level of skills, particularly over the EA land region. Striking deficiencies 
are observed over the South China Sea and western North Pacific region, where considerable model biases exist in both the amplitude and phase of the annual cycle; in addition, its interannual variability is underestimated [5].

To improve rainfall prediction over East Asia, multi-model ensemble predictions have been conducted [6,7]. Based on evaluation of the multi-model ensemble seasonal hindcasts performed by 14 climate models that participate in the Climate Prediction and its Application to Society (CliPAS) project and six models from the DEMETER project, it was shown that forecast of monsoon precipitation remains a major challenge and the seasonal rainfall predictions over land and during local summer have little skill [6]. Also, downscaling methods have been added to CilPAS prediction data to enhance prediction skill but there is no considerable improvement [7].

Recently, the third version of the Nanjing University of Information Science and Technology (NUIST) Earth System Model (hereafter, NESM3.0) has been developed to provide a numerical model for earth system studies, to project future climate changes and to simulate past climate changes, as well to conduct sub-seasonal-to-seasonal prediction. A historical experiment of the NESM3.0 based on coupled model intercomparison project phase (CMIP) 6 protocol was conducted. The results show that the NESM3.0 generally well reproduces the mean state of rainfall, EASM onset date, the leading mode of interannual variability, monsoon-ENSO relationship during mature phase and western Pacific subtropical high-East Asia rainfall teleconnection over East Asia [8].

This paper documents the seasonal prediction skills of the NESM3.0 over EA and elaborates and discusses how the significant prediction kill was achieved and what are the possible causes for the deficiencies. Section 2 introduces the NESM3.0 and presents data and initialization methods. In Section 3, we discuss how the prediction skill for EASM is improved based on the diagnostic analysis of the temporal and spatial structures of the large-scale dynamic systems. The last section presents a summary.

\section{Model, Data and Initialization}

\subsection{The NESM3.0 Model}

The newly developed NESM3.0 is a fully coupled climate system and earth system model. The ocean component of the NESM3.0 is Ocean PArallelise (OPA), which is the ocean part of the Nucleus for European Modelling of the Ocean (NEMO) v3.4 [9]. The sea ice model in the NESM3.0 is CICE v4.1 [10], which was originally developed at the Los Alamos National Laboratory. The atmosphere and land components of the NESM v3.0 are the ECHAM v6.3 atmospheric model and the associated land surface model - the Jena Scheme for Atmosphere Biosphere Coupling in Hamburg (JSBACH). The four model components are coupled through the Ocean-Atmosphere-Seaice-Soil Model Coupling Toolkit version 3.0 (OASIS3-MCT_3.0) [11], which is a fully parallelized tool to synchronize, interpolate and exchange the coupling fields among the atmospheric, oceanic and sea ice component models. The resolution of the atmospheric model is T63 horizontally (about $200 \mathrm{~km}$ ) and 47 levels vertically with $0.01 \mathrm{hPa}$ as the model top. The land surface model has the same horizontal resolution as the atmospheric model. The ocean model has a resolution of $1^{\circ}$ latitude and longitude grid with the meridional resolution being refined to $1 / 3^{\circ}$ over the equatorial region, and it has 46 vertical layers with the first 15 layers at the top $100 \mathrm{~m}$. The sea ice model resolution is about $1^{\circ}$ latitude by longitude with four sea ice layers and one snow layer on the top of the ice surface. The details of the NESM3.0 were referred to the related studies [12-14].

The ECHAM v6.3 and JSBACH models were originally developed at the Max Planck Institute [15]. The convective parameterization is based on the mass-flux framework and further modified $[16,17]$ (hereafter, TDK). The stratiform cloud scheme contains prognostic equations for the vapor, liquid, and ice phase of water, a cloud microphysical scheme, and a diagnostic cloud cover scheme. The JSBASH land surface model simulates the fluxes of energy, momentum, moisture, and tracer gases between the land surface and the atmosphere. 


\subsection{Major Improvement over the Early Version of the Model}

The early developmental version of NESM3.0 reproduces reasonably well global energy balance, climatology and major modes of climate variability but it has biases in the climatology over East Asia and western north Pacific. The model overproduces heavy rain belts over the tropical monsoon trough extending from India to the Philippine Sea. The model also underproduces major subtropical rainfall over China, Japan and Korea. The northward flow over the eastern China shifted westward and was weaker than the observations. Observed studies revealed that shallow (20-30\%) and stratiform $(60-80 \%)$ clouds occur more frequently than deep cloud (20-30\%) during summer season [18] and the contribution of stratiform rainfall to total precipitation amount is about 40-50\% [19]. However, over East Asia and western north Pacific, convective precipitation accounts for over $90 \%$ of the total precipitation in the model. This suggests that the excessive precipitation in the model may be mainly attributed to excessive deep convection, particularly in summer; hence, it is critical to suppress deep convection and enhance shallow and stratiform clouds for improvement of simulated rainfall over East Asia.

Given the problems of the early version, we needed to improve the model's capacity in simulating realistic East Asia summer monsoon while keeping global energy and water balance unaffected. For this purpose, we implemented four modified parameterizations to the NESM3.0. First, a boundary layer depth-dependent convective trigger (TRG) was added to the convective scheme to suppress deep convection [13]. This trigger function is a modified Tokioa constraint [20]. The Tokioka constraint suppresses this dry deep cloud among multiple clouds when PBL depth is relatively shallow. In this study, the Tokioka constraint was implemented in the TDK scheme, which is based on single updraft. When we simply added original Tokioka constraint in TDK scheme, the deep or middle cloud tended to be suppressed too much and large-scale condensation increased to remove accumulated convective instability, inducing increasing cloudiness. The increased cloudiness has large impact on model climatological SST and global energy balance, particularly coupled model. To reduce these negative impacts of Tokioka constraint without degrading climatology in the coupled model, we used different criteria for onset of each cloud type in the Tokioka constraint. The criteria for deep and middle convection are more released than that for shallow convection and the deep clouds can be more generated when compared to the same criteria for all cloud type. The modified Tokioka constraint is defined as

$$
\varepsilon_{\min }=\frac{\mathrm{a}_{i}}{h}
$$

where $h$ refers to the BL depth and $i$ is cloud type (deep, midlevel and shallow convection). In the original Tokioka scheme, the parameter $a$ is taken as a constant. Here, the values of $a_{i}$ are taken as 0.02, 0.015 and 0.01 for shallow, midlevel and deep convection, respectively. Note that minimum entrainment rate has normal range for each convection type. After modifying the criteria, the changes of SST and net short (long) wave radiation at the TOA are acceptable compared to those of CMIP5 models. The modified Tokioka constraint (hereafter, TRG) used in this study was implemented in the TDK scheme. Second, we added a bottom-heavy diffusivity in the shallow convection scheme (SHC) [13]. The TDK scheme used in this study includes shallow convection. In the earlier version of the NESM3.0, it was found that vertical mixing between the lower troposphere and the top of BL is insufficient (not shown). In this study, the diffusive processes in the shallow convection was added in the TDK scheme. The main difference of the shallow convection scheme used in this study and former shallow convective scheme is that our shallow convection scheme includes a specific vertical profile of vertical mixing below $600 \mathrm{hPa}$. This scheme is described by the following diffusive terms for large scale (grid mean) dry static energy $S$ and specific humidity $q$ [16]: 


$$
\begin{aligned}
& \frac{\partial \bar{s}}{\partial t}=\frac{1}{\bar{\rho}} \frac{\partial}{\partial z}\left\{\bar{\rho} K \frac{\partial}{\partial z}(\bar{s}-\mathrm{L} \bar{l})\right\} \\
& \frac{\partial \bar{q}}{\partial t}=\frac{1}{\bar{\rho}} \frac{\partial}{\partial z}\left\{\bar{\rho} K \frac{\partial}{\partial z}(\bar{q}+\bar{l})\right\}
\end{aligned}
$$

where 1 denotes cloud liquid water content, $\rho$ is the air density, $\mathrm{L}$ is the latent heat, $\mathrm{t}$ is time and $\mathrm{z}$ is height. The coefficient $\mathrm{K}$ is the eddy diffusivity, which is a prescribed function of height or pressure. To represent moisture and heat exchange between the BL and the lower troposphere, we used a modified vertical profile of diffusion coefficient in the shallow convection. The modified shallow convective scheme is effective to enhance shallow convection in the lower troposphere. Third, we changed the conversion rate from convective cloud water to rain. The changes increase moisture supply to stratiform clouds, while reducing the amount of convective precipitation. When the conversion rate decreases, less convective cloud water converts to rainfall and thus convective precipitation decreases. The remaining cloud water in the updraft is detrained to the ambient air, which leads to enhanced stratiform cloud. In this study, the conversion rate was reduced by $30 \%$ compared with original value (hereafter, CCR). This parameter could affect not only convective precipitation amount but also downdraft, re-evaporation below cloud-base and cold pool dynamics near the surface.

Fourth, the entrainment rates in deep and shallow clouds were adjusted (hereafter, ENT). An increasing entrainment rate tends to suppress deep convection. When a convective plume rises up, a large entrainment rate decreases the buoyancy of updraft quickly by enhancing mixing with relatively dry and cold environmental air; thus, cloud development tends to be suppressed. An entrainment rate was parameterized based on buoyancy $\left(\mathrm{B}_{\mathrm{u}}\right)$ and environmental relative humidity $(\mathrm{RH})$ [21]

$$
\varepsilon=\mathrm{a}_{0} * \mathrm{c}_{\varepsilon} * \mathrm{~B}_{\mathrm{u}}, \mathrm{c}_{\varepsilon}=\frac{1}{\overline{\mathrm{RH}}}
$$

where $\mathrm{c}_{\varepsilon}$ and $\mathrm{a}_{0}$ are conversion factors of environmental humidity and buoyancy on entrainment rate, respectively. When $\mathrm{RH}$ is relatively high $(>99 \%), \mathrm{c}_{\varepsilon}$ is fixed as $10^{-1}$. For smaller $\mathrm{RH}(<10 \%), \mathrm{c}_{\varepsilon}$ is 10 . The maximum (minimum) value of the entrainment rate is constrained to $10^{-3}\left(10^{-5}\right) \mathrm{m}^{-1}$.

In addition, we tuned cloud cover scheme and cloud microphysics to reduce biases in global energy balance (e.g., SST and short/long wave radiation at the top of atmosphere). Note that the modified parameterizations do not appreciably change global precipitation.

For clarity, the prediction with the earlier version of the model (without the modified parameterizations) is called the "CTL" and the prediction using the model with the modified parameterizations is called the "MOD". A parallel suite of 30-year hindcast experiments was carried out to identify and understand the impacts of the model modifications.

\subsection{The Data and Initialization}

The National Centers for Environmental Prediction-Department of Energy (NCEP-DOE) Reanalysis II data [22] were used to represent observed winds and geopotential heights. The observed precipitation data were derived from the Global Precipitation Climatology Project (GPCP) daily data [23]. For monthly mean sea surface temperature (SST), we used the National Oceanic and Atmospheric Administration Extended Reconstructed SST (ERSST) version 4 data [24].

The initialization method used for CTL and MOD is exactly the same, which is a simple three-dimensional nudging method [25]. The ocean temperature and salinity derived from the European Center for Medium-Range Weather Forecast (ECMWF) ocean reanalysis and ocean heat content datasets (ORAS4ni) were used as observations. The observed ocean data were nudged into the ocean model at all vertical layers with a specific relaxation time-scale of three days. It is noted that prediction results are not sensitive to the specified relaxation time-scale. No nudging processes were applied to the atmosphere, land and sea ice model components. 
The coupled model was integrated with the nudging process over a 22-year spin-up period (1958-1979). The entire retrospective prediction period lasts 30 years starting from 1 January 1980 to 31 December 2009. The targeted seasons are boreal summer and winter with a one-month lead time. The boreal summer (winter) prediction starts from 1 May (1 November). Each prediction contains four ensemble members. The lagged-averaged forecast (LAF) was employed for providing different initial perturbations for the ensemble members. The initial conditions for the six ensemble members were produced by one-day time lagged ensemble method during the nudging process from 25 to 30 April for the 1 May boreal summer prediction. An increase in the ensemble size with the LAF method does not contribute to the skill improvement of the prediction [25].

For simplicity, temporal correlation coefficient (hereafter, "correlation") was used to evaluate skills of the ensemble mean prediction. The correlation was obtained by calculating the correlation coefficients between the observed and predicted values of given variables during the 30-year period (1980-2009). We conducted two hindcast experiments with the CTL and MOD. In addition to the rainfall prediction, we also evaluated the predicted large-scale dynamic structure of EASM, including mean climatology, annual cycle, and major modes of interannual variability, as well as monsoon-ENSO relationship and circulation-rainfall teleconnection.

\section{Performances on Predicted EASM Rainfall}

Figure 1 presents the prediction skills of boreal summer mean precipitation over East Asia for the 30-year period (1980-2009) derived from the CTL and MOD. Only statistically significant areas are shaded (95\% confidence level). It was shown that, while the multi-model ensemble prediction has considerable prediction skill score (more than 0.5 ) over the western north Pacific, the prediction skills over the EA land regions are very low $(<0.2)$, suggesting that many climate models have no meaningful prediction skills over the continental East Asia [6]. The CTL prediction shows low skills $(<0.2)$ over the EA except over the Yangtze River Valley and Korea. The correlations averaged over the EA domain $\left(100-140^{\circ} \mathrm{E}, 5-50^{\circ} \mathrm{N}\right)$ are merely 0.02 . This is mainly attributed to the negative skills over the Eastern China Sea, southeastern China, South China Sea and Philippine Sea. The MOD prediction, in contrast, shows useful correlation scores ranging from 0.3 to 0.7 over northern China, Japan, south Korea and southeastern China, as well as Eastern and South China Sea and Philippine Sea. It is difficult to predict land monsoon rainfall due to complicated land surface conditions and atmosphere-land interaction processes. For land in East Asia, the CTL shows very low skill with a correlation of 0.03 but the MOD simulates much higher prediction skill score with a correlation of 0.34 . Comparison of the CTL and MOD confirms that the MOD improves seasonal prediction considerably over East Asia. However, low or negative skills are found over the Yangtze River Valley, north Korea and central and part of northern China. The possible reasons for the deficiency are discussed in the next section.

To examine the range of ensemble forecast and uncertainty of ensemble mean forecast, we calculated signal-to-noise ratio of precipitation prediction using all ensemble members for 30 years (Figure 2). The signal-to-noise was calculated based on [26]. In the CTL, the signal-to-noise ratios have peaks in the central China, South and Eastern China Sea, where the signal-to-noise ratios are larger than 1 . However, they are below 0.6 in other land areas, indicating that the forecast of the CTL has low reliability in East Asia land area except central China. In the MOD, the signal-to-noise ratios have relatively high values in southern and northern China, south Japan and Eastern China Sea but lower values over South China Sea and coast of China and Yangtze River Valley. In south and north China, south Japan and Eastern China Sea, both the correlation skill scores (Figure 1b) and the signal-to-noise ratios are relatively high, implying that the forecast of the MOD may be reliable and robust there. Note that the CTL and MOD have generally significant correlations where the signal-to-noise ratio is moderate or high. 
(a) CTL

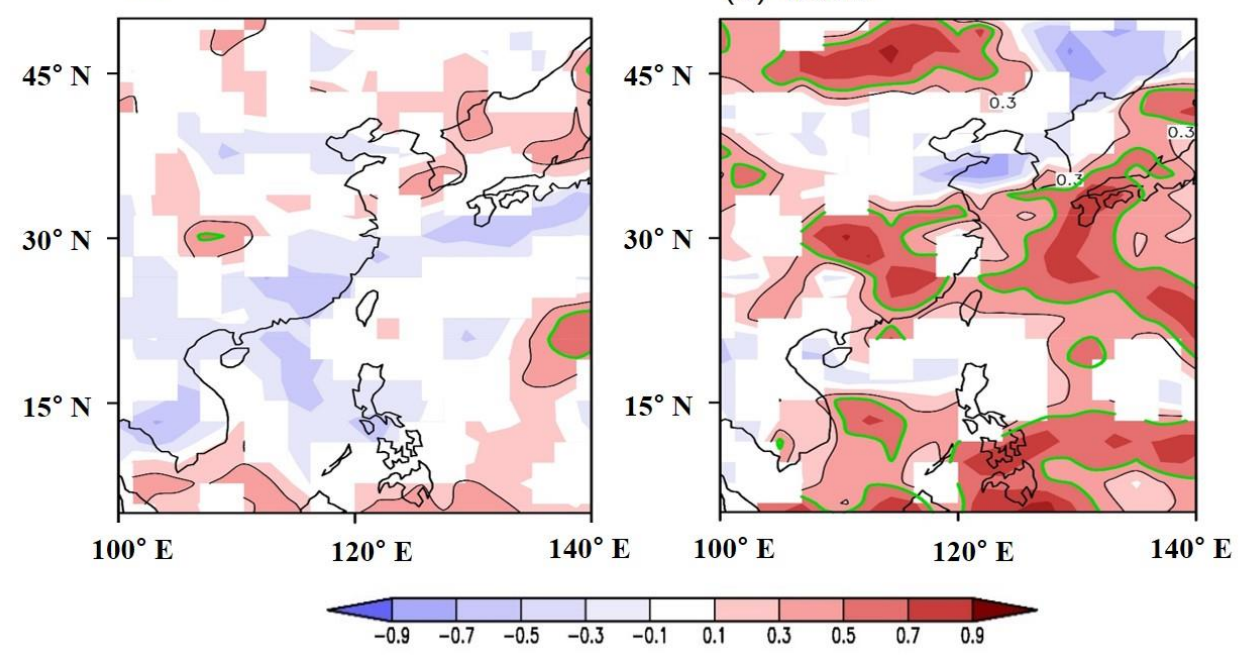

Figure 1. Temporal correlation coefficient of JJA mean precipitation from (a) the model without the modified parameterization (CTL)and (b) with the modified parameterization (MOD) over EA during 1980-2009. The green and black contours represent a coefficient of 0.5 and 0.3 , respectively. Only significant areas are shaded (95\%).

(a) CTL

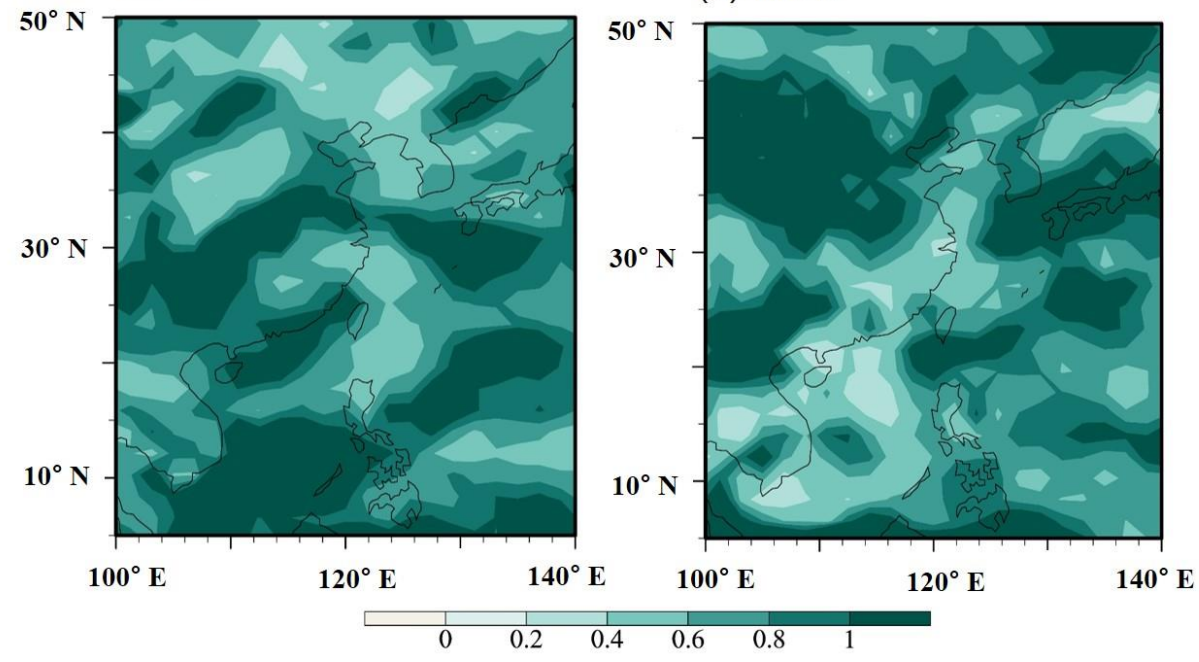

Figure 2. Signal-to-Noise ratio of precipitation forecast from: (a) CTL; and (b) MOD.

Figure 3 shows year-to-year variations of the rainfall prediction skills measured by the pattern correlation coefficient between the observed and predicted JJA precipitation anomalies over the EASM domain. The Nino3.4 index is shown in the figure to compare with the prediction skills. The CTL shows large amplitude fluctuation from year to year with moderate pattern correlation score $(\sim 0.3)$ in 1980, 1987 and 1994 and negative pattern correlations for 17 years. The 30-year averaged pattern correlation score is negative (-0.06). In the MOD, during high skill years $(1982,1993,1997,2004,2005$ and 2006), the pattern correlation scores reach about 0.62 . The lowest negative pattern correlation occurred in 2007. We compared the pattern correlation scores during the El-Nino developing and decaying years, respectively (Figure 4). The CTL has lower or negative skill during El-Nino developing and decaying years. On the other hand, the MOD has higher or moderate skill during most of the El-Nino developing and decaying years, suggesting that the improved prediction skill in the MOD may be related with ENSO simulation and its teleconnection with EASM. The details are discussed in the Section 5.2 . 
(a) CTL

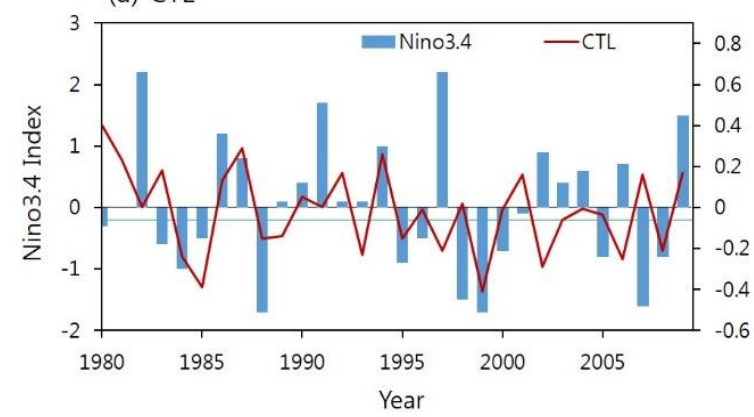

(b) MOD

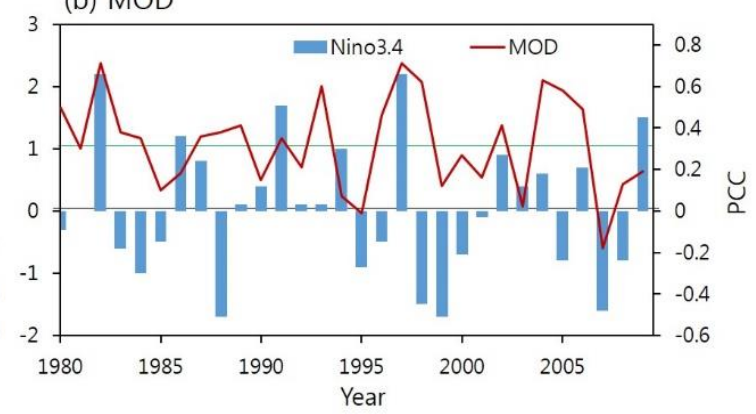

Figure 3. Year-to-year variations of the precipitation prediction skill (red line) measured by pattern correlation between observation and predicted JJA rainfall from (a) CTL and (b) MOD during 1980-2009. Pattern correlations were calculated over the EASM domain $\left(5-40^{\circ} \mathrm{N}, 100-140^{\circ} \mathrm{E}\right)$. The blue bars represent observed DJF Nino3.4 SST Index $\left({ }^{\circ} \mathrm{C}\right)$.

(a) El-Nino developing year

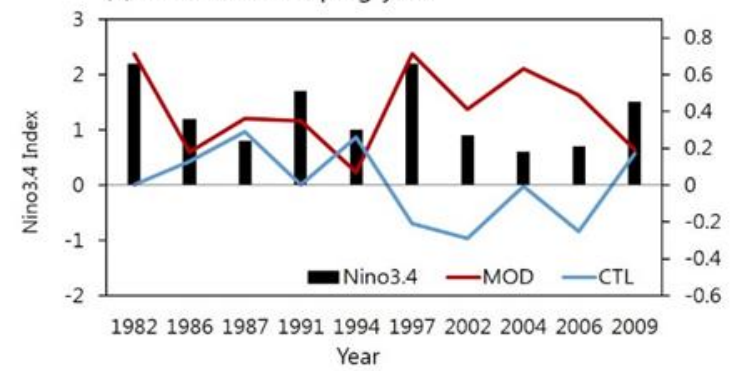

(b) El-Nino decaying year

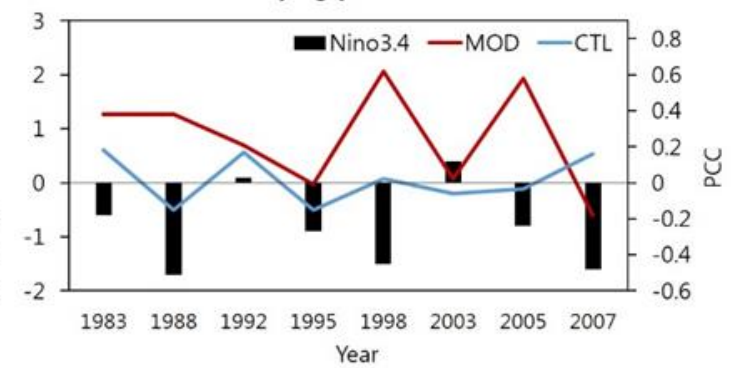

Figure 4. Same as Figure 2 except for El-Nino: (a) developing; and (b) decaying years.

\section{Sensitivity of Each Modified Parameterization on Climatology and ENSO}

Before finding the key factors that may influence the EASM prediction, we examined the effect of the modified parameterization on climatology in the East Asia and ENSO simulation.

\subsection{Climatology}

It was demonstrated that the skill for individual coupled models in predicting seasonal precipitation anomalies is positively correlated with its performances on prediction of the annual mean and annual cycle of precipitation [5]. We additionally conducted seasonal prediction using the models with each modified parameterization to see its effects on precipitation and circulation climatology in East Asia. Figure 5 shows the JJA large-scale climatological circulations and precipitation from observations and the models without the modified parameterizations (CTL), convective trigger (TRG), shallow convection (SHC), convective entrainment rate (ENT), conversion rate of cloud water to rain in the TDK scheme (CCR) and all modified parameterizations (MOD). In observations, low-level southwest monsoonal flows prevail from Arabian Sea through India and south Asia to Southern China, while southeasterlies blow from the Philippine Sea across East China Sea to Japan. In the CTL, the southwesterlies from Arabian Sea are simulated well but strong westerlies erroneously extend into the Philippine Sea and the northward flow over eastern China is weaker than the observation. In the TRG, CCR, ENT and SHC, the strong westerlies over the Philippine Sea are weakened. The TRG and ENT simulate the enhanced northward flow in the Eastern China Sea but still weaker than observation. There are no significant changes of the northward flow in the CCR and SHC. The MOD well produces southwesterlies from the Arabian Sea and the southeasterlies from the western Pacific; but the northward flow over eastern China remains weak. This may induce insufficient northward moisture transport and weak subtropical precipitation. Over East Asia, the observed major subtropical rainfall is seen over China, Japan, Korea and surrounding seas (Meiyu, Changma and Baiu), which are 
associated with the quasi-stationary East Asia subtropical front. In addition, there are heavy rain belts over the tropical monsoon trough extending from India via northern SCS to the Philippine Sea. The CTL underproduces the heavy rain belts over India and substantially overproduces heavy rain from the Bay of Bengal to western Pacific; meanwhile, the major subtropical rainfall is weaker than the observation. The TRG and SHC slightly reduce heavy rainfall over western Pacific but still stronger than the observation. The rainfall over subtropical region increased closer to the observation. The CCR largely reduces heavy rainfall from the Bay of Bengal to western Pacific but simulates similar subtropical rainfall with the CTL. There are no meaningful changes of rainfall in the ENT. The MOD improves considerably the observed patterns of the tropical rain belt except that the heavy rainfall over the eastern Bay of Bengal shifts equatorward. The magnitude of rainfall over subtropical region is increased but still weaker than observation. In sum, the CTL predicts excessive rainfall over the SCS and Philippine Sea and excessively strong monsoon trough over the Philippine Sea, but the MOD largely overcomes these deficiencies. However, the MOD still underestimates the southerly flow over the Eastern China Sea and associated subtropical frontal rainfall.

(a) OBS

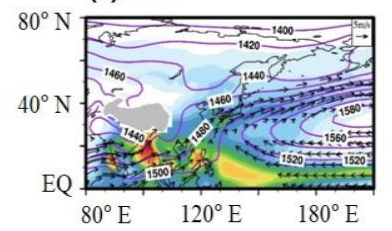

(b) CTL

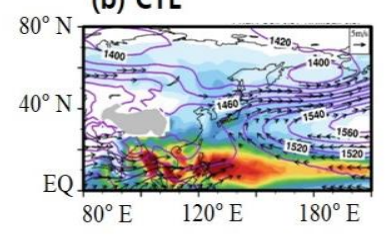

(c) TRG

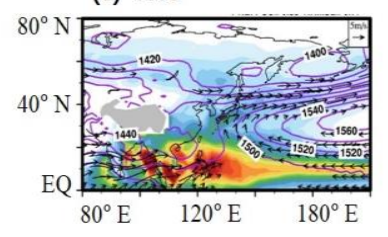

(d) ENT
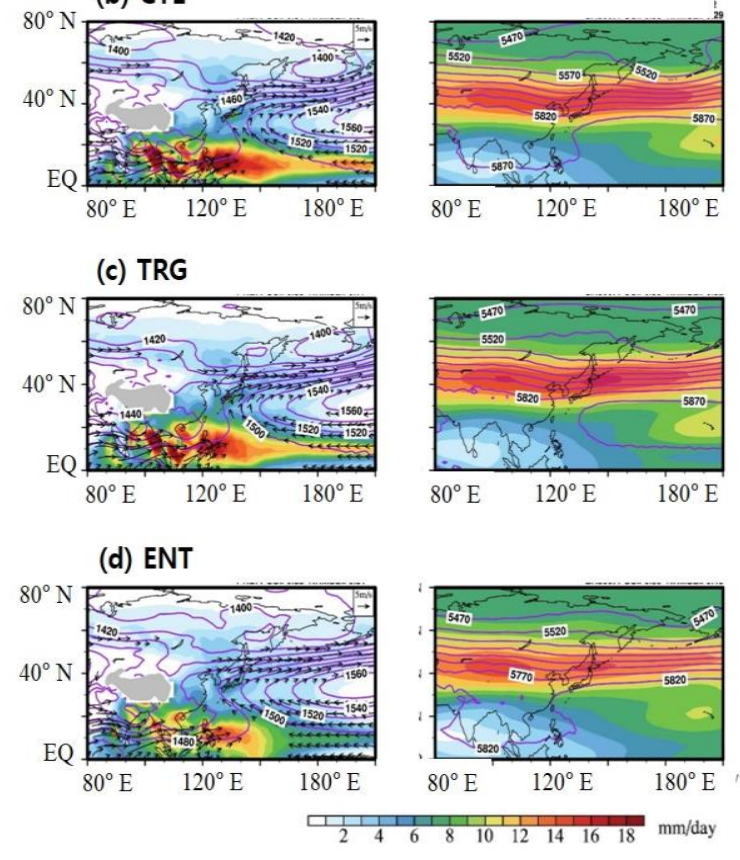

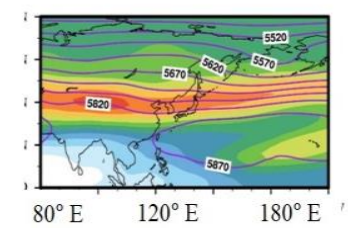

(e) $\mathrm{SHC}$

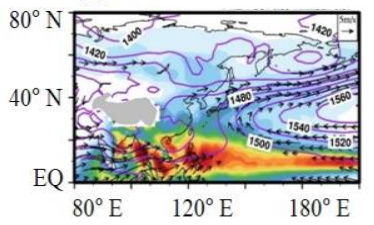

(f) $\mathrm{CCR}$

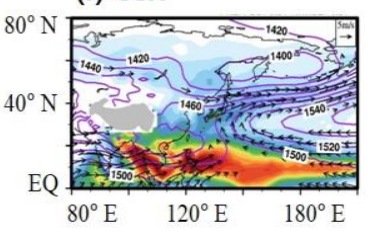

(g) MOD

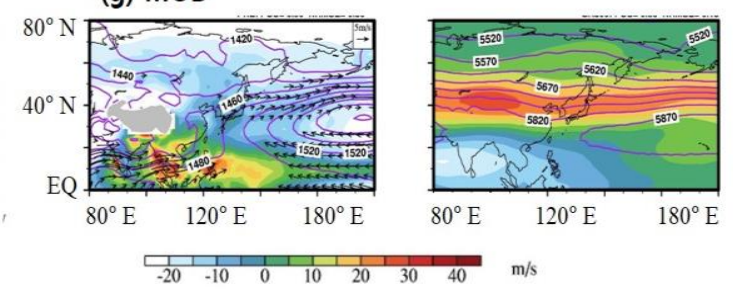

Figure 5. JJA large-scale climatology from: (a) observation; and (b-g) models. Left panels represent precipitation (shading, $\mathrm{mm} /$ day), geopotential height (contours, $\mathrm{m}$ ) and winds (vectors, $\mathrm{m} / \mathrm{s}$ ) at $850 \mathrm{hPa}$. Right panels show zonal wind at $200 \mathrm{hPa}$ (shading, m/s) and 500-hPa geopotential height (contours, m).

It is well known that the strength and location of western Pacific subtropical high and westerly jet are vitally important for the East Asia rainfall distribution and its seasonal migration [27-29]. The observed western Pacific subtropical high (outlined by the isopleth of $5870 \mathrm{~m}$ ) is over the subtropical Pacific along with strong westerly jet being located along $40^{\circ} \mathrm{N}$ and tropical easterly jet around $10^{\circ} \mathrm{N}$. In the CTL, the western Pacific subtropical high is weak and the westerly jet is stronger and broader than the observation. In the SHC, TRG and ENT, the horizontal patterns of western Pacific subtropical 
high are improved except that the western Pacific subtropical high shifts eastward. The strengths of the western Pacific subtropical high increase, which are comparable with observation. The westerly jets are slightly reduced but still stronger than observation. In the CCR, the westerly jet is much reduced and its magnitude is comparable with the observation but the western Pacific subtropical high is not strengthened. In the MOD, the horizontal pattern of the $500 \mathrm{hPa}$ geopotential height is improved. The magnitude of western Pacific subtropical high is comparable with observation except its location is slightly shifted eastward. The observed westerly jet is well represented in the MOD although its magnitude is slightly greater than observation. The results here suggest that the MOD has a potential for better EASM prediction by improved large-scale climatology compared to the CTL. We also see the horizontal pattern of tropical Pacific precipitation regressed onto Niño-3.4 index in Figure 6. The observations show wet anomalies in the central and eastern Pacific due to warm SST anomalies, while dry anomalies in the western Pacific. The peak of precipitation occurs near the date line. There is meridional asymmetry of rainfall anomalies in the eastern Pacific. The wet anomalies occur at north of the equator and no change in the south. The CTL overproduces the rainfall anomalies, particularly in the central Pacific. The wet anomalies extend westward to the western Pacific. In the north of the eastern Pacific, wet anomalies are stronger than observation. There are wet anomalies in the south of the eastern Pacific, which are not observed. In the TRG, the wet anomalies in the central and eastern Pacific are stronger than the CTL. The dry anomalies over western Pacific erroneously extend to central Pacific. In the ENT, the wet anomalies are reduced but still stronger than observation and dry anomalies extend from western to eastern Pacific. In the SHC, horizontal patterns of the rainfall anomalies are similar to observation except the south of the eastern Pacific and its magnitude is much reduced closer to observation. The CCR underproduces the wet anomalies over equatorial Pacific but horizontal pattern is improved compared with the CTL. The MOD reproduces horizontal pattern of rainfall anomalies and the magnitude is comparable with the observation. The wet anomalies over the south of the eastern Pacific are almost removed. The results indicate that the MOD could captures the change of precipitation during warm event, which may contribute to better EASM-ENSO relationship.

(a) OBS

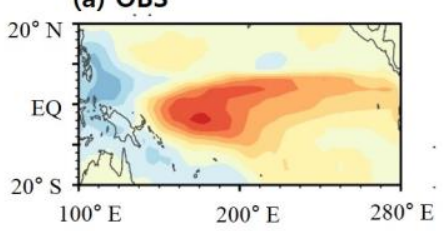

(b) CTL

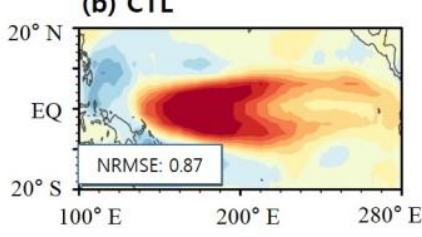

(e) SHC

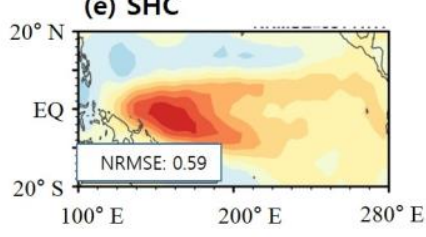

(c) TRG

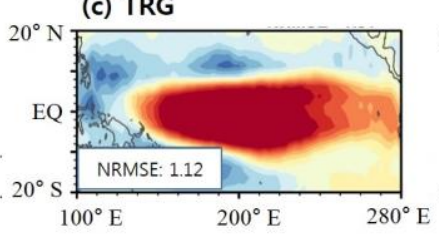

(d) ENT

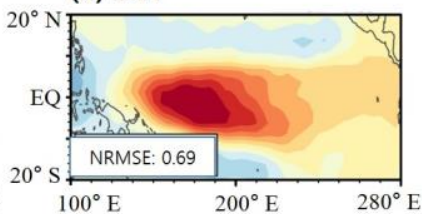

(g) MOD

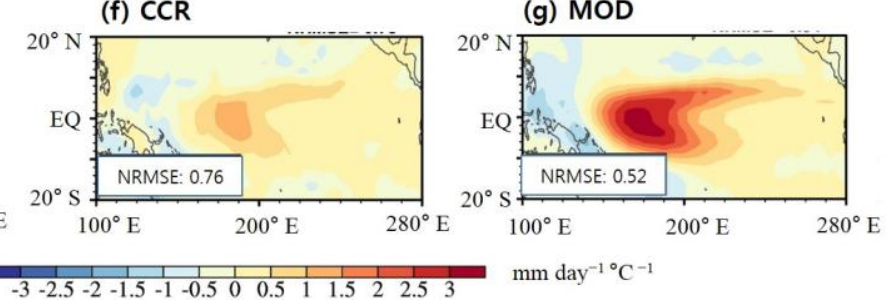

Figure 6. Precipitation anomalies regressed onto Nino-3.4-averaged SST anomalies, all months included (mm day ${ }^{-1}{ }^{\circ} \mathrm{C}^{-1}$ ) from: (a) observation; and $(\mathbf{b}-\mathbf{g})$ NESM3.0 simulations with the modified parameterizations. 


\subsection{ENSO}

Figure 7 shows horizontal pattern of interannual variability of SST anomalies from observation and the model experiments. In the observations, the SST anomalies have peaks in the eastern Pacific and along the coast of South America. In the CTL, SST anomalies are overproduced in the equatorial Pacific and extend to western Pacific. In the TRG, the horizontal pattern of the variability is not improved; its magnitude is stronger than the CTL and extends to the west. In the ENT, the variability is slightly decreased but still stronger than observation. The variability simulated in the SHC is comparable with observation but extends westward. Noted that the changes in the TRG and ENT are consistent with previous studies $[30,31]$. The CCR underproduces the variability, which is much smaller than the observation. The MOD reproduces the horizontal pattern of the variability well except along coastline of South America. The magnitude of variability is comparable with observation and the westward extension is reduced. The results suggest that the MOD has a potential for better EASM prediction by enhanced horizontal pattern and magnitude of ENSO interannual variability compared to the CTL.

(a) OBS

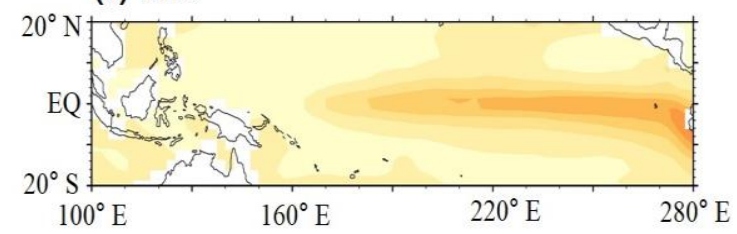

(b) CTL

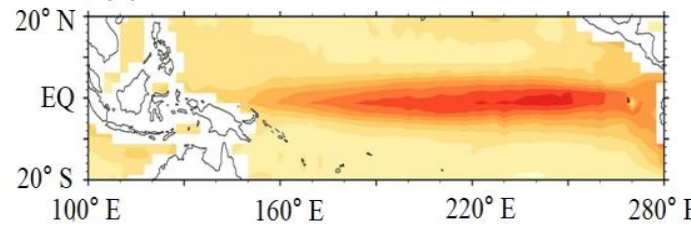

(c) TRG

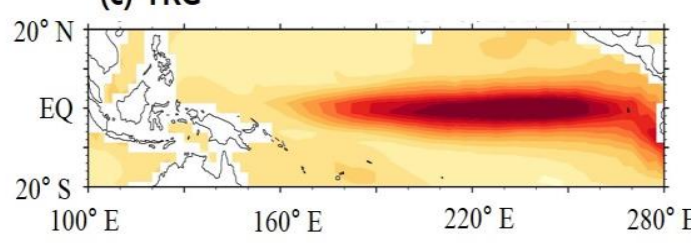

(d) ENT

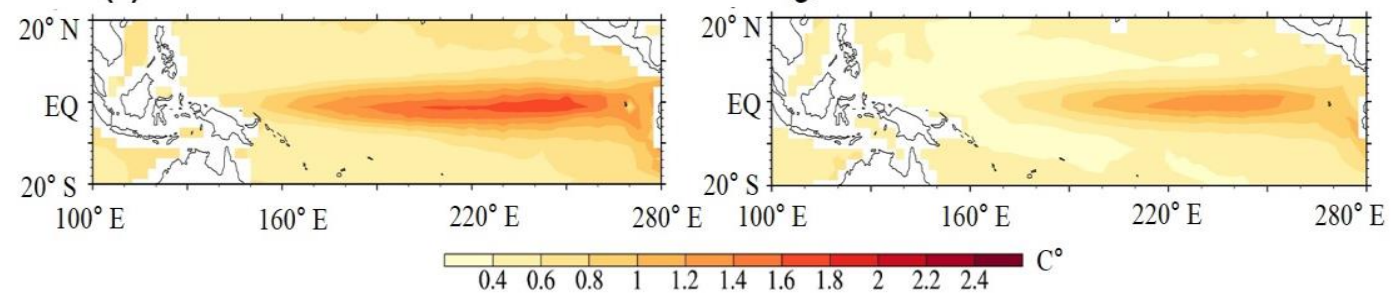

(e) $\mathrm{SHC}$

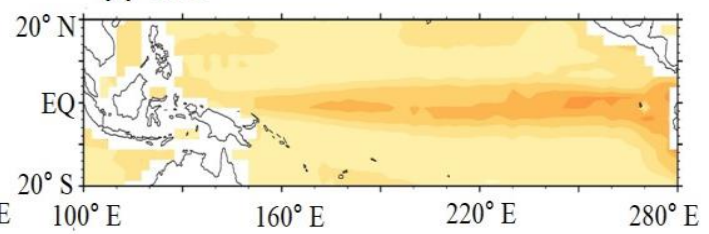

l (f) CCR

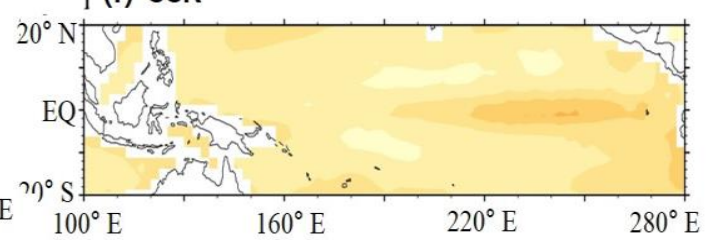

(g) MOD

Figure 7. Standard deviation of interannual variability of monthly SST anomalies $\left({ }^{\circ} \mathrm{C}\right)$ from: (a) observation; and (b-g) NESM3.0 simulations with the modified parameterizations.

\section{Evaluation of Predicted Climatology and Major Modes of Variability}

To find the reasons for the useful skills and deficiencies of the models' predictions, we tried to analyze and identify the key factors that may influence the EASM prediction. These factors include predicted seasonal transition, the major modes of interannual variability, predicted Pacific SST anomalies and ENSO-EASM teleconnection, as well as the predicted WPSH and associated rainfall anomalies. 


\subsection{Seasonal Transition}

For skillful prediction of EASM rainfall, it is of preeminent importance to accurately simulate the seasonal transition from the dry to rainy seasons and associated northward movement of the Meiyu-Baiu rain belt [32]. Figure 8 shows a latitude-time diagram of the observation and predicted pentad mean rainfall from the CTL and MOD, averaged between $110^{\circ} \mathrm{E}$ and $130^{\circ} \mathrm{E}$. Before mid-May, there are two major observed rainfall belts: (1) zonal band over $15^{\circ} \mathrm{S}-5^{\circ} \mathrm{N}$; and (2) subtropical band over EA $\left(20^{\circ} \mathrm{N}-35^{\circ} \mathrm{N}\right)$. The later reflects spring rainy season over southern China. In mid-late May, the two rainfall belts merge together near $10^{\circ}-25^{\circ} \mathrm{N}$ over the South China Sea. Around mid-June, the rainfall belt originally located at South China continuously moves northward up to $40^{\circ} \mathrm{N}$ and remains there until August. The CTL predicts the transition of rainfall reasonably well, but tropical rain belt is overproduced while the summer subtropical rain is weaker than the observation. A more severe problem is that the CTL failed to predict northward propagation of rain belt from $25^{\circ} \mathrm{N}$ to $40^{\circ} \mathrm{N}$. On the other hand, the MOD prediction simulated reduced tropical rain belt. The subtropical monsoon rainfall over north of $20^{\circ} \mathrm{N}$ is slightly better than observation but northward migration of the subtropical rain belt remains insufficient during August. The pattern correlation and normalized root mean square errors of the CTL are 0.86 and 0.96 , respectively, while corresponding values of the MOD are 0.89 and 0.75 , suggesting that the MOD improves the magnitude in seasonal transition of precipitation in East Asia rather than horizontal pattern. The changes made in MOD may be expected to have a positive influence on the rainfall anomaly prediction over the northern EA.

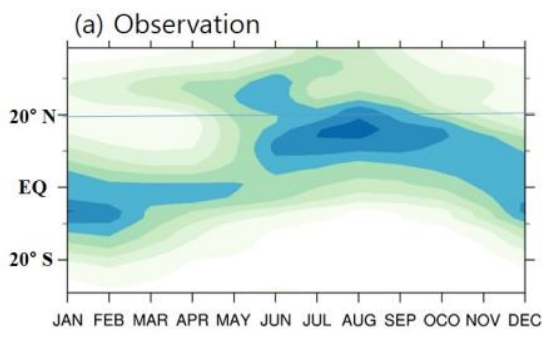

(b) CTL

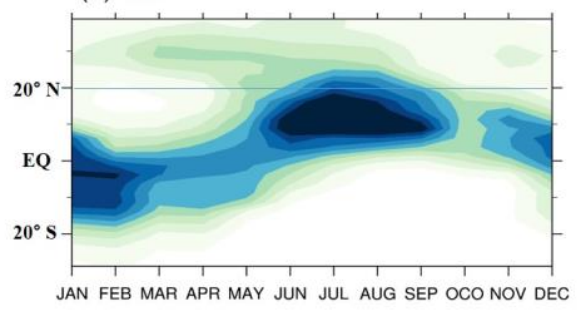

(c) MOD

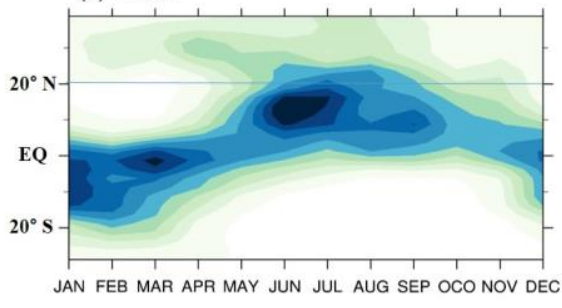

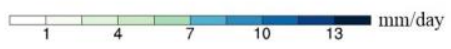

Figure 8. Annual cycle climatology (1980-2009) for pentad mean precipitation averaged between $110^{\circ}$ E and $130^{\circ}$ E from: (a) observation; (b) CTL; and (c) MOD. The blue horizontal line shows $20^{\circ} \mathrm{N}$.

\subsection{ENSO Prediction and EASM-ENSO Relationship}

ENSO has been recognized as the dominant source of predictability of EASM, which strongly affects EASM during both the ENSO developing and decaying summers [32,33]. Reliable seasonal forecast should rely on realistic prediction of ENSO and the EA rainfall and circulation system associated with it.

Figure 9 displays correlation skill of the models for Nino 3.4 SST anomalies as a function of forecast lead time. The North American Multi-model ensemble [34] is also shown in the figure to compare with the prediction skills. The correlation score of the CTL is 0.80 for boreal summer (averaged over the lead time of 1-3 months) but drops to 0.6 at six-month lead. The summer mean skill score is much lower than the NMME and it is similar with the skill of the lowest dynamic model in the NMME members. The correlation score of the MOD is 0.87 for boreal summer and reaches 0.72 for six-month 
lead. The correlation score of the MOD is almost the same as the NMME skill, suggesting that the MOD has considerably improved ENSO prediction skill.

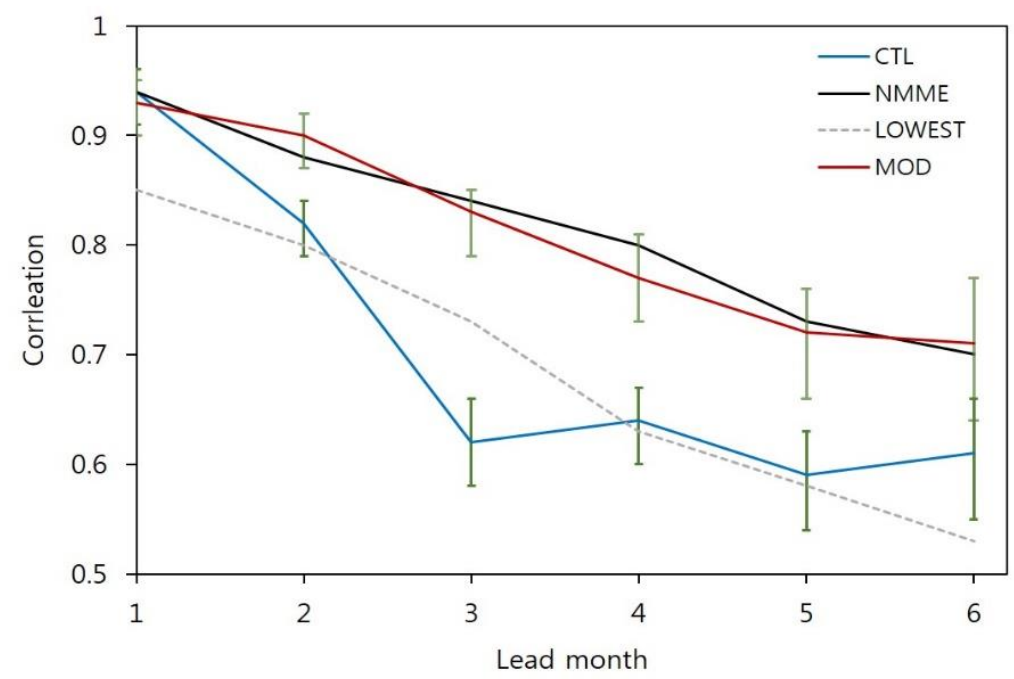

Figure 9. Correlation skill of the June-August mean Nino 3.4 SST index from CTL (blue), MOD (red), NMME (black) and lowest dynamic models (gray dashed) from NMME project as a function of lead month. The forecast starts from 1 May. The green vertical bars represent the ensemble spread using each member.

It is well known that EASM responds to ENSO differently in the developing and decaying summers. To this end, we examine the observed and model predicted EASM-ENSO relationship during the El Nino developing and decaying summers, separately. The El Nino developing summers include 1982, 1986, 1987, 1991, 1994, 1997, 2002, 2004, 2006 and 2009. The El Nino decaying summers are 1983, 1988, 1992, 1995, 1998, 2003, 2005, and 2007. Figure 10 shows composite EASM precipitation and circulation anomalies derived from observation and predicted by the CTL and MOD. During El Nino developing summers, the observed summer rainfall deceases over central East Asia but increases over southern East Asia, in accordance with the cyclonic anomalies over southern East Asia and the anticyclonic anomalies over northern China. The CTL captures the dry anomalies over central and Eastern China Sea but fails to simulate the wet anomalies over southern East Asia. Corresponding westerlies over the South China Sea and Philippine Sea are simulated in the CTL but anomalous easterlies shift to Korea. The anticyclonic anomalies over the northern China are not simulated in the CTL. The pattern correlation (normalized root-mean-square error) of precipitation anomalies in the CTL is 0.35 (1.85), indicating that the CTL poorly simulates rainfall and circulation anomalies during El-Nino developing summer. The MOD captures the dry anomalies well over central and northern East Asia and the wet anomalies over southern East Asia and western Pacific as well as the cyclonic anomalies over southern East Asia. However, the magnitudes of circulation and rainfall anomalies are too strong. There is also a wet bias in northern China. The pattern correlation (normalized root-mean-square error) of precipitation anomalies in the MOD is 0.53 (1.25), suggesting that the MOD predictions are improved but the pattern correlation score is not high.

During El Nino decaying summer, observation displays dry rainfall anomalies over the South China Sea and Philippine Sea and wet anomalies over Meiyu front, which correspond to an anticyclonic anomaly in the South China Sea and Philippine Sea. The CTL failed to capture both the dry anomalies over southern East Asia (except over the Philippine Sea) and the wet anomalies over central China (Meiyu front) and Korea. The corresponding anticyclonic anomalies in the South China Sea and Philippine Sea are overproduced. The pattern correlation (normalized root-mean-square error) of precipitation anomalies in the CTL is 0.20 (1.95). The MOD simulates more realistic dry anomalies over the South China Sea and the wet anomalies north of $25^{\circ} \mathrm{N}$ but with strong dry biases over the 
northern East China. The anticyclonic anomalies in the MOD is similar with the observed counterparts. Generally, the MOD well reproduces rainfall anomalies related with ENSO over the southern and northern East Asia, where its prediction skill tends to be higher than other regions. Similarly, the CTL has better rainfall anomalies around Korea, where the prediction skill is relatively high. The pattern correlation (normalized root-mean-square error) of precipitation anomalies in the MOD is 0.47 (1.1), suggesting that the MOD predictions are slightly improved. The results suggest that a better EASM-ENSO relationship may contribute to the improvement of rainfall prediction skill.

(a) Observation

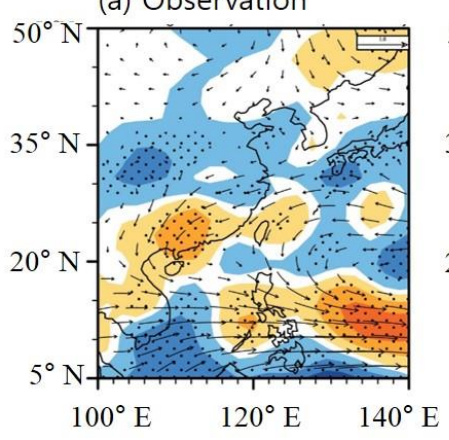

(b) CTL

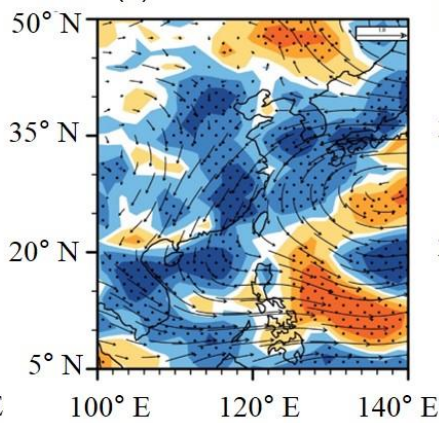

(c)MOD

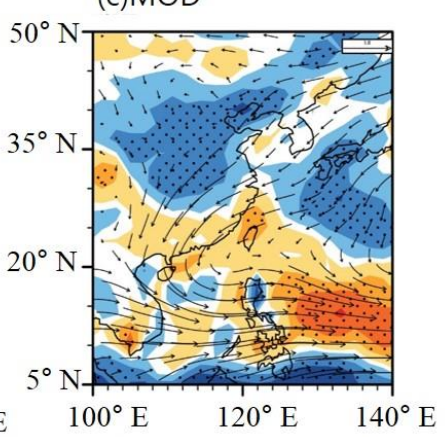

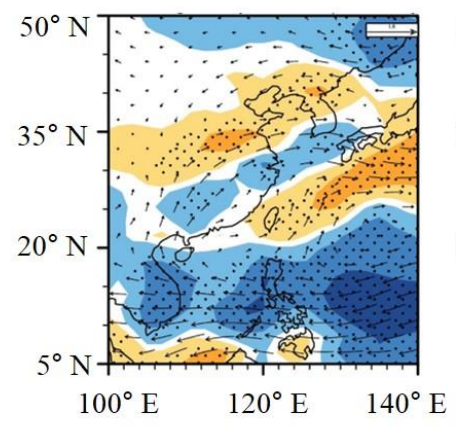
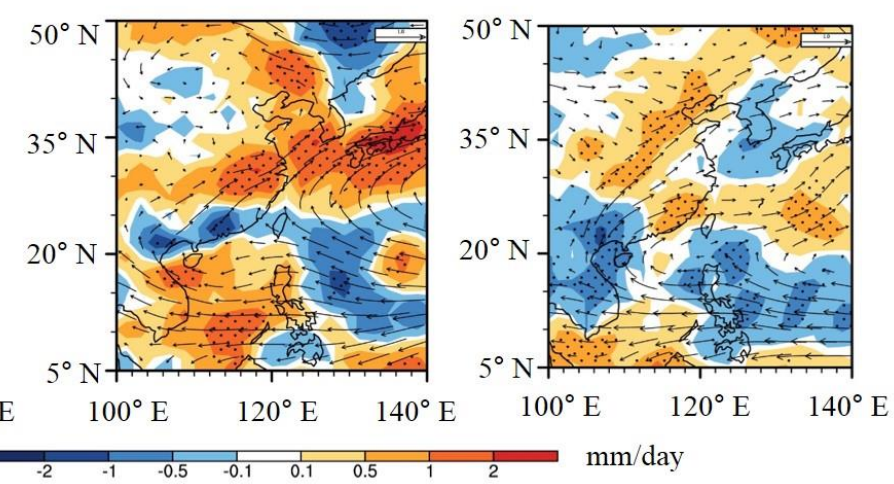

Figure 10. Composite maps of JJA rainfall (shading, $\mathrm{mm} \mathrm{day}^{-1}$ ) and $850 \mathrm{hPa}$ winds (vector, $\mathrm{m} \mathrm{s}^{-1}$ ) anomalies from: (a) observation; (b) CTL; and (c) MOD during El-Nino developing (upper panels) and decaying year (lower panels). The only significant areas are dotted (95\%) (Ambaum 2010).

Figure 11 shows composite rainfall, wind and divergence anomalies of observation and models for El Nino developing and decaying periods. During El Nino developing periods, the observation shows strong wet anomalies in the western Pacific and along ITCZ. The wet anomalies extend westward to Philippine Sea and South China Sea. Strong dry anomalies occur in the Maritime continent and eastern Indian Ocean. In central China and south Japan, weak dry anomalies occur. Strong divergence exists in the region with strong wet anomalies-western Pacific, ITCZ, Philippine Seas and Bay of Bengal. Corresponding strong easterlies flow from eastern to western Pacific and westerlies from Japan to north of eastern Pacific. The westerlies wind in the southern East Asia flow from India via Eastern China Sea to Japan. In the CTL, the peak of wet anomalies is located at western Pacific and IPCZ but overproduce it in northern central Pacific. The westward extension of wet anomalies is weakened east of the Philippine Sea. The CTL failed to capture wet anomalies in the south China and Taiwan. The CTL also overproduces dry anomalies from central EA land via Eastern China Sea to east of Japan. The divergence anomalies are also overestimated in the equatorial and northern central Pacific. The strong wet anomalies generate anticyclonic anomalies in northern Pacific and thus easterlies from eastern Pacific shift to south. The weakened easterlies from western Pacific Sea may result in stronger westerlies from India, which flow via Korea and Japan to northern Pacific, than the observations. 
(a) Observation

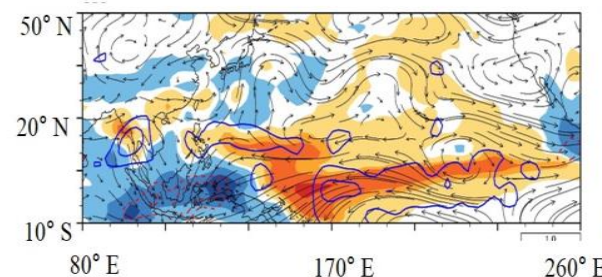

(b) CTL

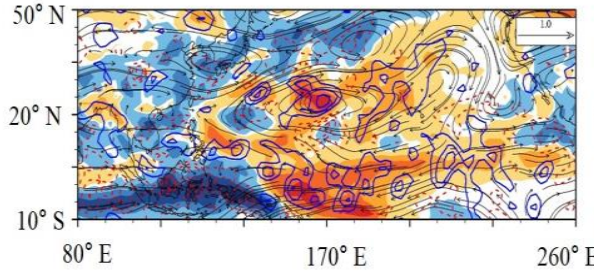

(c) MOD

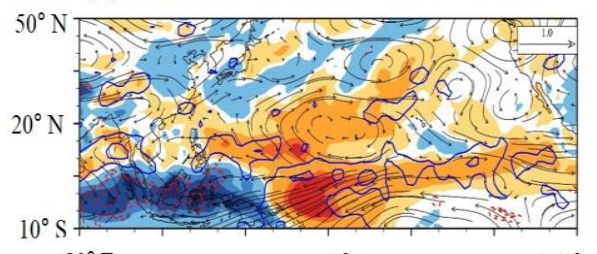

$80^{\circ} \mathrm{E}$

$170^{\circ} \mathrm{E}$

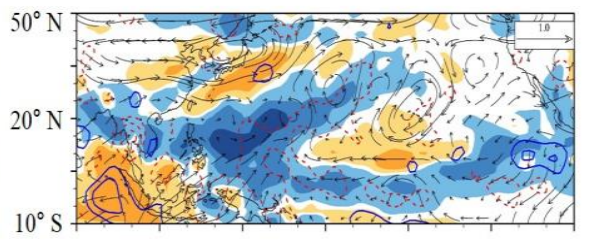

$80^{\circ} \mathrm{E}$

$170^{\circ} \mathrm{E}$

$260^{\circ} \mathrm{E}$

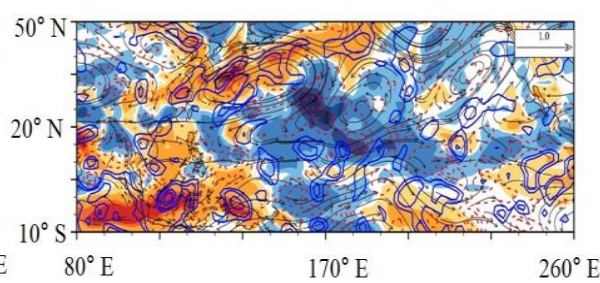

$260^{\circ} \mathrm{E}$

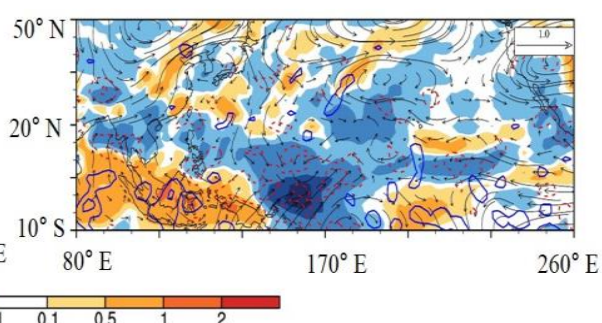

Figure 11. Composite maps of JJA rainfall (shading, $\mathrm{mm} \mathrm{day}^{-1}$ ), divergence (blue contour, day ${ }^{-1}$ ), convergence (red contour, $\mathrm{day}^{-1}$ ) and $200 \mathrm{hPa}$ winds (vector, $\mathrm{m} \mathrm{s}^{-1}$ ) anomalies from: (a) observation; (b) CTL; and (c) MOD during El-Nino developing (left panels) and decaying year (right panels). The contour starts from \pm 0.02 and intervals are 0.04 .

The MOD reproduces horizontal pattern of rainfall anomalies well except northern central Pacific. The wet anomalies in the western Pacific extend to South China Sea and Philippine Sea. The wet anomalies in the northern central Pacific are reduced compared with the CTL. In East Asia, the MOD captures wet anomalies in south China and dry anomalies in central China and south Japan. However, there are wet biases in western China near Yangtze River Valley, where the correlation skill of rainfall prediction is relatively low (Figure 1). The horizontal patterns of divergence anomalies are similar with the observations. The anti-cyclonic anomalies in the northern central Pacific and the westerlies in the central China are reduced closed to the observation.

In the decaying summers, the observations show strong dry anomalies from India via South China Sea to western Pacific. They extend to northern east Pacific and along ITCZ to coastline of South America. In East Asia, dry anomalies occur in south China and wet anomalies in central China, north Korea and south of Japan. The convergence anomalies are located where strong dry anomalies occur. Corresponding anti-cyclonic anomalies are observed in the northern central Pacific and cyclonic anomalies in the Korea and Japan. In the CTL, the wet anomalies are overproduced in the northern central Pacific and west of north America and do not extend to South China Sea and Bay of Bengal. The wet anomalies in the Maritime continent extend to the north and thus the CTL fails to capture dry anomalies in the Southeast Asia. The wet anomalies in central China, Koran and Japan are overproduced and erroneously extend to northern east Pacific. The convergence and divergence anomalies are overproduced in most of the tropical Pacific and East Asia, which result from the biases of the precipitation anomalies. There are large biases in the circulation, particularly central Pacific and Northeast Asia. In the MOD, the horizontal patterns of rainfall anomalies are enhanced in the northern central Pacific, Philippine and South China Seas, and Bay of Bengal. The MOD reproduces 
dry anomalies in the south China and wet anomalies in central East Asia. The horizontal patterns of divergence (convergence) anomalies are also improved due to enhanced wet (dry) anomalies. The cyclonic anomalies in the north East Asia are well captured in the MOD but shift to north. The MOD also captures anti-cyclonic anomalies in the northern central Pacific. The results suggest that the MOD improves rainfall anomalies and associated divergent flow, particularly El Nino developing summers.

\subsection{Major Modes of Interannual Variability of EASM}

Besides climatology, it is important to see the model's capability in predicting intrinsic modes of interannual variability. We argue that models with better intrinsic modes of interannual variability may improve EASM prediction. To depict the major modes of variability, it is suggested multivariate EOF analysis (MV-EOF) by analyzing a set of meteorological and oceanographic fields [35]. The leading MV-EOF mode can be a good indicator for estimating variability of EASM that has special structures in both precipitation and circulation systems.

(a) Observation

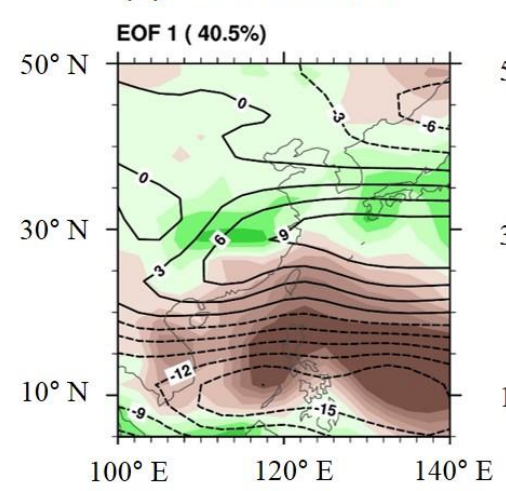

(d) CTL (PCS)

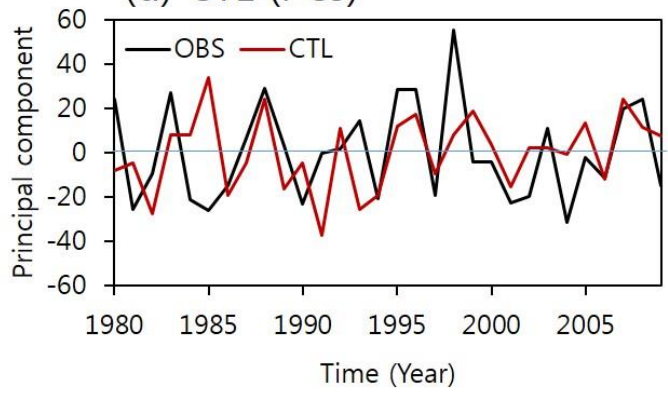

(b) CTL

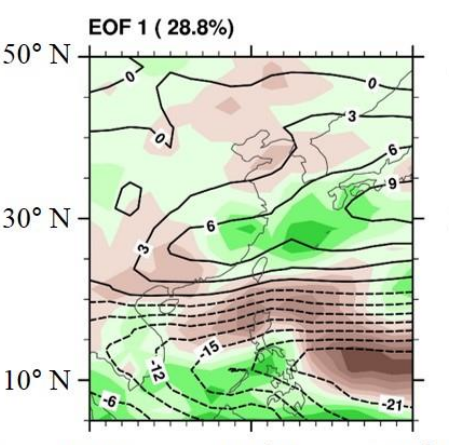

(c) $M O D$

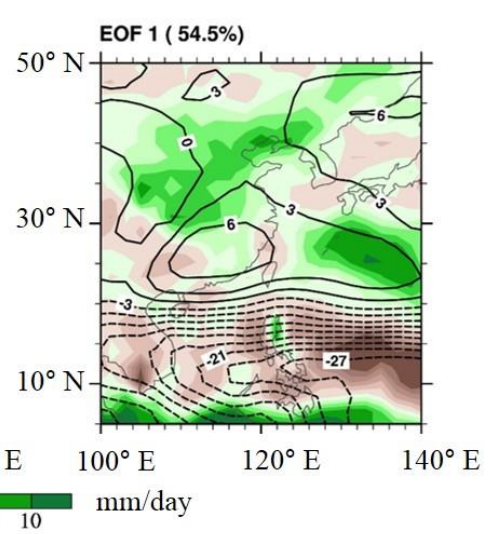

(e) MOD (PCs)

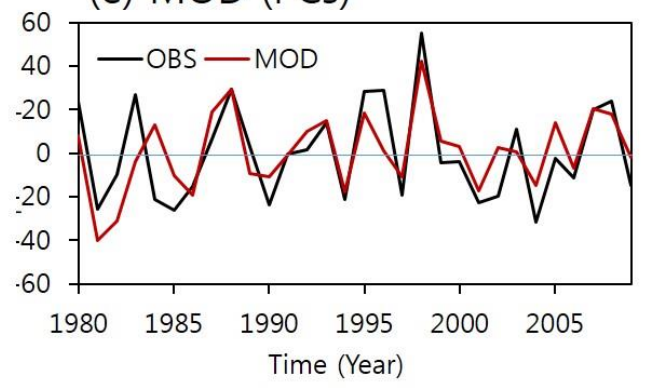

Figure 12. Spatial patterns of first MV-EOF modes of JJA mean precipitation (shadings, $\mathrm{mm} \mathrm{day}^{-1}$ ) and 850-hPa zonal wind (contour, $\mathrm{m} \mathrm{s}^{-1}$ ) from: (a) observation; (b) CTL; and (c) MOD during 30 years (1980-2009). Lower panels represent corresponding principal components from: (d) CTL; and (e) MOD.

Figure 12 (upper panels) shows the first MV-EOF mode of the JJA precipitation and $850 \mathrm{hPa}$ zonal winds anomalies from the observation and predicted by the models. The observation displays dry rainfall anomalies over the South China Sea and Philippine Sea and wet anomalies over Meiyu front region, which correspond to an anticyclonic anomaly in the South China Sea and Philippine Sea and a cyclonic anomaly located to the east of Korea with a relatively weak magnitude. The CTL captures dry anomalies over the Philippine Sea but there is strong wet bias over the South China Sea. The CTL also poorly produces the wet anomaly along the subtropical frontal zone from the southern to west Japan. The MOD has an overall similar performance and deficiencies as in the CTL but captures dry anomalies in the South China Sea and wet anomalies in central China and North Korea. The western Pacific anticyclonic anomalies are weak and the cyclonic anomalies northeast of Korea are missed 
in both the CTL and MOD. The rainfall anomalies over the subtropical East Asia, especially over the Yangtze River Valley are totally missed, which is partially responsible for the low skills over the Yangtze River Valley in the MOD prediction.

The interannual variation of the corresponding principal component of the first mode is shown in Figure 12d,e. The observed principal components generally have higher (lower) value in El-Nino decaying (developing) year. The principal components of CTL are weakly correlated with the observed principal components (correlation: 0.28 ), while the PCs from the MOD and observation are significantly correlated but the correlation (0.61) is not very high.

\subsection{Prediction of EASM Circulation Index and Associated Rainfall Anomaly Pattern}

Previous studies have shown that the models have better ability to predict the circulation anomalies over the western north Pacific and East Asia region, although precipitation anomalies are poorly predicted [36]. We examined whether the prediction using circulation anomalies is consistent with correlation of precipitation anomalies. The variation of the western north Pacific-EASM circulation system is well depicted by the meridional zonal wind shear (vorticity) index defined by $850 \mathrm{hPa}$ zonal wind averaged over $\left(22.5-32.5^{\circ} \mathrm{N}, 110-140^{\circ} \mathrm{E}\right)$ minus that over $\left(5-15^{\circ} \mathrm{N}, 90-130^{\circ} \mathrm{E}\right)$ proposed by Wang and Fan (1999). This index captures variations of the western north Pacific tropical monsoon trough, the western Pacific subtropical high and associated subtropical frontal zone [37]. The strength and location of the western Pacific subtropical high is one of the dominant factors for East Asia rainfall (Zhou et al. 2009b; Wang et al. 2013) and it represents well the leading mode of EASM variations [37]. Figure 13 shows prediction skill score for the index. The observation displays that positive (negative) index tends to be related with El-Nino decaying (developing) year. The CTL performs poorly in capturing the year-to-year variability with a correlation score of 0.20 . The MOD simulates the interannual variability of WF index reasonably well with a correlation of 0.64 . This is consistent with the improved MOD performance in predicting the EASM-ENSO relationship (Figure 10).

(a) CTL

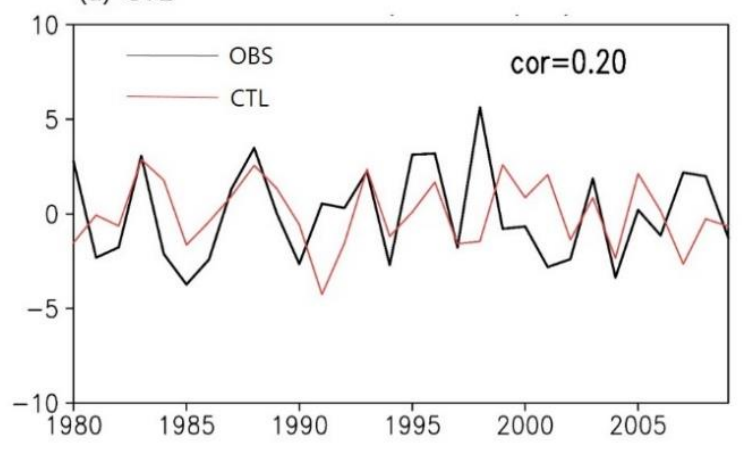

(b) MOD

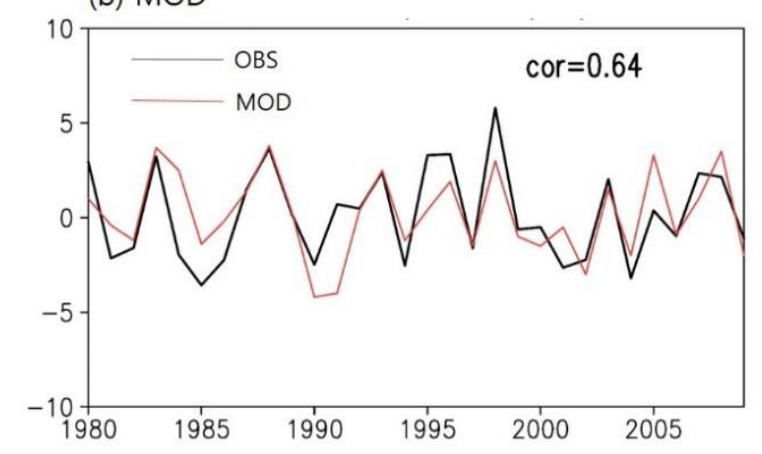

Figure 13. Year-to-year variations of the Wang and Fan index $\left(\mathrm{m} \mathrm{s}^{-1}\right)$ from: (a) CTL; and (b) MOD. The WF index is defined by zonal wind at $850 \mathrm{hPa}$ over $\left(22.5-32.5^{\circ} \mathrm{N}, 110-140^{\circ} \mathrm{E}\right)$ minus $\left(5-15^{\circ} \mathrm{N}\right.$, 90-130 E). The black line represents observed WF.

\section{Conclusions and Discussion}

This study assessed the seasonal prediction skill of the Nanjing University of Information Science and Technology Earth System Model (NESM3.0) for East Asia Summer Monsoon (EASM). The earlier version of NESM3.0 has poor performance in seasonal prediction of EASM. To improve the model prediction, the convective parameterization schemes were modified to suppress excessive deep convection and enhance insufficient shallow and stratiform clouds over the tropics (Section 2.2). The new version of NESM3.0 with modified parameterizations (MOD) yields markedly improved rainfall prediction in large areas of EA land regions except over the Yangtze River Valley (YRV) 
(Figure 1). Diagnostic analyses based on large-scale dynamic structure were carried out to find key processes responsible for better prediction and remaining deficiencies. It was found that the improved prediction is primarily attributed to the improvements in the MOD predicted: (i) climatological summer mean rainfall especially over the WP monsoon trough and the WP subtropical high (Figure 5); (ii) the ENSO prediction (Figure 9); and (iii) the EA rainfall anomalies associated with the development and decay of El Nino events (Figure 10). However, the MOD still has notable biases in the predicted leading mode of interannual variability of precipitation. The leading mode captures the dry (wet) anomalies over the South China Sea (northern EA) but misplaces precipitation anomalies over the Yangtze River Valley and along the subtropical front in general (Figure 12). The model can capture the interannual variation of the circulation indices very well (Figure 13). The results here suggest that, over EA land regions, the skillful rainfall prediction relies on not only model's capability in predicting better summer mean, ENSO simulation, and ENSO teleconnection with EASM, but also accurate prediction of the leading modes of interannual variability, especially the anomalous western Pacific subtropical high and its connections with the EA rainfall. The results here also suggest that a model with better dynamics structure may reproduce better prediction of precipitation over EA. This issue will be studied in the future.

This study focused on large-scale dynamic structure to reveal which processes are critical to improved prediction. However, other physical processes (e.g., thermodynamic, moisture, land surface feedback, etc.) may all contribute to prediction skill of rainfall over EA. These invite future studies. It would be worthwhile to estimate impacts of each large-scale dynamic features on improved prediction and clearly identify how they contributed to the improvements. However, this requires a large set of multi-model ensemble hindcast data. This is another topic for future study. While we have assessed the impacts of the modified parameterizations as a whole on EASM prediction, an explanation for how each modified parameterization affects seasonal prediction skill remains difficult. Since many modifications in the physical processes were employed in the model, additional experiments need to be conducted to identify the effects of each modification.

Although notable improvement has been made in the model, there remains large room for further improvement. Previous studies suggested that deficit of cloud physics or convective parameterization in the models results in low prediction skill (Lee et al., 2010; Seo et al., 2015). The introduction of stochastic parameters in the major physical processes (e.g., convective parameterization and cloud microphysics) can be one of the solutions to improve parameterization because it is difficult to find accurate parameter values. In addition, adapting more advanced initialization methods (e.g., Ensemble Kalman filter) may increase predictability. These will be the subjects of further study.

Author Contributions: Writing—original draft, Y.-M.Y.; and Writing—review and editing, B.W. and J.L.

Funding: This research was funded by National Natural Science Foundation of China (Grant No. 41605035, Grant No. 41420104002) and the National Key Research and Development Program of China (Grant No. 2016YFA0600401) as well as the National Science Foundation (Climate Dynamics Division) Award No. AGS-1540783.

Acknowledgments: This is Publication No. 1352 of IPRC, and Publication No. 242 of the Earth System Modeling Center (ESMC).

Conflicts of Interest: The authors declare no conflict of interest.

\section{References}

1. Kang, I.S.; Jin, K.; Wang, B.; Lau, K.M.; Shukla, J.; Krishnamurthy, V.; Schubert, S.; Wailser, D.; Stern, W.; Kitoh, A.; et al. Intercomparison of the climatological variations of Asian summer monsoon precipitation simulated by 10 GCMs. Clim. Dyn. 2002, 19, 383-395.

2. Wang, B.; Zhang, Y.; Lu, M. Definition of South China Sea Monsoon Onset and Commencement of the East Asia Summer Monsoon. J. Clim. 2004, 17, 699-710. [CrossRef]

3. Wang, B.; Ding, Q.; Fu, X.; Kang, I.-S.; Jin, K.; Shukla, J.; Doblas-Reyes, F. Fundamental challenge in simulation and prediction of summer monsoon rainfall. Geophys. Res. Lett. 2005, 32, L15711. [CrossRef] 
4. Tompkins, A.M.; Ortiz De Zarate, M.I.; Saurral, R.I.; Vera, C.; Saulo, C.; Merryfield, W.J.; Sigmond, M.; Lee, W.S.; Baehr, J.; Braun, A.; et al. The Climate-System Historical Forecast Project: Pro-viding Open Access to Seasonal Forecast Ensembles from Cen-ters around the Globe, B. Am. Meteorol. Soc. 2017, 98, 2293-2302. [CrossRef]

5. Lee, J.-Y.; Wang, B.; Kang, I.S.; Shukla, J.; Kumar, A.; Kug, J.S.; Schemm, J.K.E.; Luo, J.J.; Yamagata, T.; Fu, X.; Alves, O. How are seasonal prediction skills related to models performance on mean state and annual cycle? Clim. Dyn. 2010, 35, 267-283. [CrossRef]

6. Wang, B.; Lee, J.-Y.; Kang, I.-S.; Shukla, J.; Park, C.K.; Kumar, A.; Schemm, J.; Cocke, S.; Kug, J.S.; Luo, J.J.; et al. Advance and prospectus of seasonal prediction: As-sessment of the APCC/CliPAS 14-model ensemble retrospective seasonal prediction (1980-2004). Clim. Dyn. 2009, 33, 93-117. [CrossRef]

7. Lee, D.Y.; Ahn, J.-B.; Yoo, J.-H. Enhancement of seasonal prediction of East Asian summer rainfall related to western tropical Pacific convection. Clim. Dyn. 2015, 45, 1025-1042. [CrossRef]

8. Juan, L.; Wang, B.; Yang, Y.-M. A comprehensitve diagnostics metrics for evaluation and assessment of East Asian monsoon. J. Clim. 2018, submitted.

9. Madec, G. NEMO Ocean Engine; Note du Pole de modélisation, Institut Pierre-Simon Laplace (IPSL): Paris, France, 2008.

10. Hunke, E.C.; Lipscomb, W.H. CICE: The Los Alamos Sea Ice Model Documentation and Software User's Manual; Version 4.0, LA-CC-06-012; Los Alamos National Laboratory: New Mexico, NM, USA, 2008.

11. Valcke, S.; Craig, T.; Coquart, L. OASIS3-MCT User Guide(OASIS3-MCT 1.0); CERFACS: Toulouse, France, 2012.

12. Cao, J.; Wang, B.; Yang, Y.-M.; Ma, L.; Li, J.; Sun, B.; Bao, Y.; He, J.; Zhou, X. The nuist earth system model (nesm) version 3: Description and preliminary evaluation. Geosci. Model Dev. Discuss. 2018, 1, 2975-2993. [CrossRef]

13. Yang, Y.-M.; Wang, B. Improving MJO simulation by enhancing the interaction between boundary layer convergence and lower tropospheric heating. Clim. Dyn. 2018. [CrossRef]

14. Yang, Y.-M.; Wang, B.; Lee, J.-Y. Mechanisms of northward propagation of boreal summer Intraseasonal Oscillation revealed by climate model experiments. Geophys. Res. Lett. 2018, submitted.

15. Stevens, B.; Giorgetta, M.; Esch, M.; Mauritsen, T.; Crueger, T.; Rast, S.; Salzmann, M.; Schmidt, H.; Bader, J.; Block, K.; et al. The Atmospheric Component of the MPI-M Earth System Model: ECHAM6. J. Adv. Model. Earth Syst. 2017, 5, 146-172. [CrossRef]

16. Tiedtke, M. A comprehensive mass flux scheme for cumulus parameterization in large-scale models. Mon. Weather Rev. 1989, 117, 1779-1800. [CrossRef]

17. Nordeng, T.E. Extended Versions of the Convective Parametrization Scheme at ECMWF and Their Impact on the Mean and Transient Activity of the Model in the Tropics; European Centre for Medium-Range Weather Forecasts: Reading, UK, 1994.

18. Wen, M.; Yang, S.; Kumar, A.; Zhang, P. An Analysis of the Large-Scale Climate Anomalies Associated with the Snowstorms Affecting China in January 2008. Mon. Weather Rev. 2009, 137, 1111-1131. [CrossRef]

19. Yang, S.; Smith, E.A. Convective-stratiform precipitation variability at seasonal scale from $8 \mathrm{yr}$ of trmm observations: Implications for multiple modes of diurnal variability. J. Clim. 2008, 21, 4087-4114. [CrossRef]

20. Tokioka, T.; Yamazaki, K.; Kitoh, A.; Ose, T. The equatorial 30-60 day oscillation and the Arakawa-Schubert penetrative cumulus parameterization. J. Meteorol. Soc. Jpn. 1988, 66, 883-901.

21. Kim, D.; Kang, I.-S. A bulk mass flux convection scheme for climate model: Description and moisture sensitivity. Clim. Dyn. 2012, 38, 411-429. [CrossRef]

22. Kanamitsu, M.; Ebisuzaki, W.; Woollen, J.; Yang, S.-K.; Hnilo, J.J.; Fiorino, M.; Potter, G.L. NCEP-DOE AMIP-II Reanalysis (R.-2). Bull. Am. Meteorol. Soc. 2002, 83, 1631-1643. [CrossRef]

23. Adler, R.F.; Huffman, G.J.; Chang, A.; Ferraro, R.; Xie, P.P.; Janowiak, J.; Rudolf, B.; Schneider, U.; Curtis, S.; Bolvin, D.; Gruber, A. The Version-2 Global Precipitation Climatology Project (GPCP) Monthly Precipitation Analysis (1979-Present). J. Hydrometeorol. 2003, 4, 1147-1167. [CrossRef]

24. Huang, B.; Thorne, P.W.; Smith, T.M.; Liu, W.; Lawrimore, J.; Banzon, V.F.; Zhang, H.M.; Peterson, T.C.; Menne, M. Further Exploring and Quantifying Uncertainties for Extended Reconstructed Sea Surface Temperature (ERSST) Version 4 (v4). J. Clim. 2015, 29, 3119-3142. [CrossRef]

25. Kang, I.S.; Jang, P.H.; Almazroui, M. Examination of multi-perturbation methods for ensemble prediction of the MJO during boreal summer. Clim. Dyn. 2014, 42, 2627-2637. [CrossRef] 
26. George, S.E. Predictability and skill of boreal winter forecasts made with the ECMWF seasonal forecast system II. Q. J. R. Meteorol. Soc. 2006, 132, 2031-2053. [CrossRef]

27. Zhou, T.-J.; Yu, R.-C. Atmospheric water vapor transport associated with typical anomalous summer rainfall patterns in China. J. Geophys. Res. Atmos 2005, 110, D8. [CrossRef]

28. Zhou, W.; Chan, J.C.L.; Chen, W.; Ling, J.; Pinto, J.G.; Shao, Y. Synoptic-Scale Controls of Persistent Low Temperature and Icy Weather over Southern China in January 2008. Mon. Weather Rev. 2009, 137, 3978-3991. [CrossRef]

29. Wang, B.; Xiang, B.; Lee, J.-Y. Subtropical High predictability establishes a promising way for monsoon and tropical storm predictions. Proc. Natl. Acad. Sci. 2013, 110, 2718-2722. [CrossRef]

30. Kim, D.; Jang, Y.S.; Kim, D.H.; Kim, Y.H.; Watanabe, M.; Jin, F.F.; Kug, J.S. El Niño-Southern Oscillation sensitivity to cumulus entrainment in a coupled general circulation model. J. Geophys. Res. 2011, 116, D22112. [CrossRef]

31. Watanabe, M.; Chikira, M.; Imada, Y.; Kimoto, M. Convective control of ENSO simulated in MIROC. J. Clim. 2011, 24, 543-562. [CrossRef]

32. Wang, B.; Li, J.; He, Q. Variable and robust East Asian monsoon rainfall response to El Niño over the past 60 years (1957-2016). Adv. Atmos Sci. 2017, 34, 1235-1248. [CrossRef]

33. Huang, R.; $\mathrm{Wu}, \mathrm{Y}$. The influence of ENSO on the summer climate change in China and its mechanism. Adv. Atmos Sci. 1989, 6, 21-32.

34. Kirtman, B.P.; Min, D.; Infanti, J.M.; Kinter, J.L., III; Paolino, D.A.; Zhang, Q.; van den Dool, H.; Saha, S.; Mendez, M.P.; Becker, E. The North American Multi-Model Ensemble (NMME): Phase-1 Seasonal to Interannual Prediction, Phase-2 Toward Developing Intra-Seasonal Prediction. Bull. Am. Meteorol. Soc 2014, 95, 585-601. [CrossRef]

35. Wang, B. The vertical structure and development of the ENSO anomaly mode during 1979-1989. J. Atmos Sci. 1992, 49, 698-712. [CrossRef]

36. Fan, K.; Liu, Y.; Chen, H. Improving the prediction of the East Asian summer monsoon: New approaches. Weather Forecast. 2012, 27, 1017-1030. [CrossRef]

37. Wang, B.; Wu, Z.; Li, J.; Liu, J.; Chang, C.P.; Ding, Y.; Wu, G. How to measure the strength of the East Asian summer monsoon. J. Clim. 2008, 21, 4449-4463. [CrossRef] 